\title{
Influence of Cerebral Ischemia of Various Duration on Mitochondrial Respiration
}

\author{
Nataliya Yaugenievna Maksimovich ${ }^{1,2}$, Tatsiana Sergeevna Milosh ${ }^{1,2}$, Iosif Karlovich Dremza ${ }^{1,2}$ \\ ${ }^{1}$ Department of Pathophysiology of the Name of D. A. Maslakov, Grodno State Medical University, Grodno, Belarus \\ ${ }^{2}$ Department of Obstetrics and Gynecology, Grodno State Medical University, Grodno, Belarus
}

Email address:

mne@grsmu (N.Y.Maksimovich), milashts@mail.ru (T. S. Milosh), idremza@rambler.ru(I. K. Dremza)

\section{To cite this article:}

Nataliya Yaugenievna Maksimovich, Tatsiana Sergeevna Milosh, Iosif Karlovich Dremza. Influence of Cerebral Ischemia of Various Duration on Mitochondrial Respiration. Bioprocess Engineering. Vol. 2, No. 1, 2018, pp. 6-9. doi: 10.11648/j.be.20180201.12

Received: February 21, 2018; Accepted: March 11, 2018; Published: April 8, 2018

\begin{abstract}
Estimation of the energy exchange parameters during partial brain ischemia offers an opportunity for finding new ways of correcting the above pathology. The aim of the study was to investigate the changes in mitochondrial respiration in the homogenates of rats with brain cerebral ischemia of various duration. The experiment was carried out on 19 white female rats in whom the right common carotid artery was ligated for 1 hour or 3 days with subsequent decapitation and brain removal. The rate of mitochondrial respiration in mitochondrial suspension of brain homogenates was assessed by means of the polarographic method using succinate or a mixture of L-malate/L-glutamate and adenosine diphosphate as respiratory substrates. Ligation of the right common carotid artery of various duration resulted in reduced mitochondrial respiration rate which was more pronounced after 1 hour of partial brain ischemia as compared to 3 hours. Modeling of partial cerebral ischemia in rats by ligation of the right common carotid artery considerably inhibits respiratory activity of the brain mitochondria leading to the dissociation of oxidation and phosphorylation in the mitochondria and inducing impairment of neuronal bioenergetics in cerebral tissue due to the disturbance of the supply of oxygen by blood. Understanding of pathophysiological processes in mitochondria during partial brain ischemia will help to develop new methods of pathogenetic correction of changes in cell structures of the brain tissue. This approach offers new possibilities for the pathogenetic therapy.
\end{abstract}

Keywords: Rats, Brain, Partial Ischemia, Mitochondrial Respiration

\section{Introduction}

The relevance of cerebrovascular diseases of ischemic genesis is indisputable since they are associated with high morbidity, mortality and disability worldwide. Strokes head all other cerebrovascular diseases. Recently, a rise in the incidence of acute cerebrovascular accidents has been noted, particularly among the working-age population - those up to 64 years [4].

Morbidity and mortality rates from stroke remain among highest in Belarus. According to the official statistics the incidence of strokes in the republic is 296 cases per 100,000 people [14], in the Russian Federation - 350-400 cases per 100,000 people [13], which is $2-2.5$ times higher than in the European countries.

The annual death-rate from ischemic stroke among the active population in the Republic of Belarus corresponds to $25.1 \%$ per 100 thousand population [2] and in the RF -374 per 100 thousand people [12], which is 4 times as high as in Canada and USA [1]. According to the World Health Organization [15] stroke ranks second as a cause of death worldwide.

It has been established that cerebral ischemia is a complex of pathobiochemical and pathophysiological processes. An acute lack of oxygen supply to the brain, inhibition of aerobic and activation of anaerobic pathway of glucose utilization, ATP deficit, impairment of ion transport, acid-base balance disturbances are the key mechanisms which trigger necrotic and programmed death of neurones [4-9]. Brain injury is associated with altered protein synthesis, inflammation as well as oxidative and nitrosative stress.

The researchers have established the role of nitric oxide in the pathogenesis of cerebral tissue damage during subtotal ischemia [7]. Morphological examination of the brain of rats with partial brain ischemia revealed paretic expansion of blood vessels and their fullness, stasis, erythrocyte sludge, oedema [10]. 
However, the pathogenesis of cerebral ischemia, associated with disturbances in energy production, still remains unclear. In this context, the use of an experimental model with brain ischemia of various duration can contribute to studying the mechanisms of transient and stable ischemic lesions, which is important for finding new ways of their correction.

The aim of the study was to investigate the changes in mitochondrial respiration (MR) in the homogenates of rats with brain cerebral ischemia of various duration.

\section{Materials and Methods}

\section{Animals, chemicals and experimental design}

Nineteen white mongrel female rats weighing 180-220g, which were observed according the principles of humane treatment of animals, were used in the experiments. The use of females for the study is due to the possibility of performing ovariectomy in order to study its effects on the course of energy metabolism disorders in the brain of experimental animals with partial ischemia. All the requirements of the Helsinki Declaration on the Humane Treatment of Animals (2000), as well as the European Parliament and Council Directive №2010/63/EU of 22.09.2010 on the protection of animals used for scientific purposes were carried out during the experiments [3] and in accordance with the norms adopted by the ethical commission for the humane treatment of animals of the Grodno State Medical University.

The study was performed using three groups of rats which were kept in standard vivarium conditions. First two groups of animals underwent the brain partial ischemia (BPI) that was performed by ligation of the right common carotid artery [5]: BPI with one-hour duration for group №1 $(n=6)$ and three days duration BPI for group №2 $(n=6)$. The third group $(n=7)$ comprised the control sham operated rats. At the end of the ischemic period, the anesthetized animals (sodium thiopental, $60 \mathrm{mg} / \mathrm{kg}$ body weight, intramuscularly) underwent the blood drawing by catheterization of the common carotid artery; the brain drawing was performed after decapitation of rats. The brain was removed "in the cold" $\left(0-4^{\circ} \mathrm{C}\right)$, drained off with filter paper, weighed and homogenized in isolation medium $(0.25 \mathrm{M}$ sucrose, $0.02 \mathrm{M}$ Tris- $\mathrm{HCl}$ and $0.001 \mathrm{M}$ EDTA, $\mathrm{pH}$ 7.2) in $1: 10$ correlation, using a Potter-Evelheim homogenizer with a Teflon pestle, according to the modified classical method of Lai and Clark (1974) [6].

The mitochondria were isolated by differential centrifugation at a temperature of $0-4^{\circ} \mathrm{C}$. The rate of MR was recorded polarographically depending on the change in the oxygen content in the mitochondrial suspension with a Clarke platinum-silver electrode which was embedded in a thermostated sealed polarographic cell with a volume of 1.75 $\mathrm{ml}$ at $27 \mathrm{C}$. [11]. Activation of MR was initiated by the administration of such substrates as succinate $(5 \mathrm{mM})$ or Lmalate/L-glutamate ( 2 and $5 \mathrm{mM})$. After this, adenosine diphosphate (ADP) was added to the cell and ADP- stimulated respiration $(200 \mu \mathrm{M})$ was studied.

Using polarograms, the speed of MR of various metabolic states was calculated: $\mathrm{V}_{1}$ - the rate of endogenous (basal) respiration, $\mathrm{V}_{2}$ - the rate of substrate-dependent respiration, $\mathrm{V}_{3}$ - the rate of respiration coupled with phosphorylation (after ADP administration), $\mathrm{V}_{4}$ - the rate of respiration after consumption of ADP (figure1).

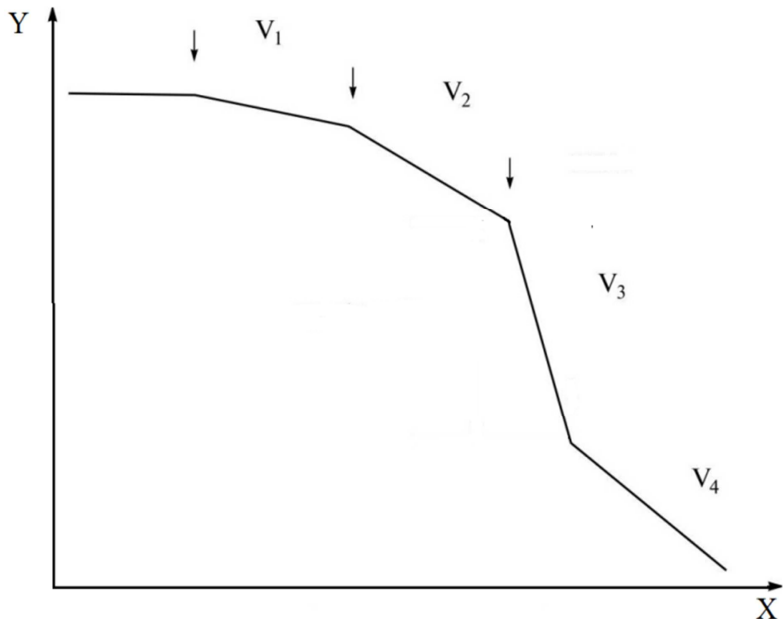

Figure 1. The curve of oxygen consumption by isolated rat brain mitochondria in different metabolic states.

Notes:

Along the $\mathrm{Y}$ axis, the mitochondrial respiration rates (ng at $\mathrm{O}_{2} / \mathrm{min} / \mathrm{mg} /$ protein) are denoted: $\mathrm{V}_{1}-$ is the rate of endogenous (basal) respiration, $\mathrm{V}_{2}$ - is the velocity of the substrate of dependent respiration, $\mathrm{V}_{3}$ is the rate of ADP-dependent respiration, $\mathrm{V}_{4}-$ is the respiratory rate after completion phosphorylation of ADP.

Along the $\mathrm{X}$ axis, the arrows from the left to the right indicate the moments of successive introduction into the cell: mitochondria, substrates (succinate or a mixture of malate / glutamate), ADP.

The coefficients characterizing $\mathrm{MR}$ were the acceptor control ratio $\left(\mathrm{ACR}=\mathrm{V}_{3} / \mathrm{V}_{2}\right)$, the respiratory control ratio $\left(\mathrm{RCR}=\mathrm{V}_{3} / \mathrm{V}_{4}\right)$ and the conjugation of the oxidation and phosphorylation processes - the phosphorylation coefficient - adenosine three-phosphate/oxygen (ATP/O). Statistical data processing was performed by non-parametric methods using the Statistica 10 program. To assess the statistical significance of the differences, the Mann-Whitney and Kruskel-Wallis test was used. Differences were considered statistically as significant at $\mathrm{p}<0.05$.

\section{Results}

There was a significant decline in the majority of MR rates in the group of animals with 1 hour BPI compared with group of sham operated rats. So, after using succinate as the substrate for respiration, there was a drop in all parameters: in the rate of basal respiration $\left(\mathrm{V}_{1}\right)$ by $17.6 \%(\mathrm{p}<0.05)$, in the rate of substrate induced respiration $\left(\mathrm{V}_{2}\right)$ by $31.7 \%(\mathrm{p}<$ $0.05)$, in the rate of ADP stimulated respiration $\left(\mathrm{V}_{3}\right)$ by $41.7 \%(\mathrm{p}<0.05)$, in the respiration rate after ADP administration $\left(\mathrm{V}_{4}\right)$ by $27.2 \%(\mathrm{p}<0.05)$, accounting for $82.4 \%, 68.3 \%, 58.3 \%$ and $72.8 \%$, respectively, of the values in the control group (table 1). There was a significant decrease in the coefficient of respiratory control $\left(\mathrm{V}_{3} / \mathrm{V}_{4}\right)$ by $25.7 \%(\mathrm{p}<0.05)$ and coefficient of phosphorylation $(\mathrm{ATP} / \mathrm{O})$ by $35.7 \%(\mathrm{p}<0.05)$. 
Group of rats with 3 days partial cerebral ischemia (PCI) compared with sham operated animals had the tendency to decrease in $\mathrm{V}_{1}$ - by $13.4 \%(\mathrm{p}>0.05)$ and considerable drop in following parameters: $V_{2}-$ by $17.4 \%(p<0.05), V_{3}-$ by $25.6 \%(\mathrm{p}<0.05), \mathrm{V}_{4}-$ by $18.5 \%(\mathrm{p}<0.05)$.

Table 1. Changes in the rates of oxygen consumption by rat brain mitochondria and the ACR, RCR, ATP/O coefficients after brain partial ischemia (BPI) of different duration.

\begin{tabular}{|c|c|c|c|c|}
\hline \multirow{2}{*}{ Indicators/Unit of substrate } & \multirow{2}{*}{ Substrate } & \multicolumn{3}{|l|}{ Groups of rats } \\
\hline & & Control group & 1 hour BPI & 3 days BPI \\
\hline \multirow{2}{*}{$\mathrm{V}_{1}\left(\mathrm{ng}\right.$ atom $\mathrm{O}_{2} / \mathrm{min} / \mathrm{mg} /$ protein $)$} & malate / glutamate & $15.2(14.3 ; 15.9)$ & $13.7(11.2 ; 16.6)$ & $14.3(10.2 ; 15.6)$ \\
\hline & succinate & $14.2(13.8 ; 16.0)$ & $11.7 *(9.2 ; 14.6)$ & $12.3(9.2 ; 14.6)$ \\
\hline \multirow{2}{*}{$\mathrm{V}_{2}\left(\mathrm{ng}\right.$ atom $\mathrm{O}_{2} / \mathrm{min} / \mathrm{mg} /$ protein $)$} & malate / glutamate & $29.1(26.8 ; 31.9)$ & $20.3 *(14.7 ; 31.5)$ & $24.2 *(22.9 ; 28.2)$ \\
\hline & succinate & $28.1(25.8 ; 30.9)$ & $19.2 *(13.7 ; 30.4)$ & $23.2 *(20.9 ; 26.2)$ \\
\hline \multirow{2}{*}{$\mathrm{V}_{3}\left(\mathrm{ng}\right.$ atom $\mathrm{O}_{2} / \mathrm{min} / \mathrm{mg} /$ protein $)$} & malate / glutamate & $42.0(36.5 ; 44.8)$ & $24.9 *(22.6 ; 28.3)$ & $32.5 *(23.2 ; 36.0)$ \\
\hline & succinate & $41.0(34.5 ; 42.6)$ & $23.9 *(22.4 ; 27.3)$ & $30.5 *(21.2 ; 34.0)$ \\
\hline $\mathrm{V}_{4}\left(\mathrm{ng}\right.$ atom $\mathrm{O}_{2} / \mathrm{min} / \mathrm{mg} /$ protein $)$ & succinate & $24.3(22.9 ; 25.5)$ & $17.7 *(13.8 ; 21.4)$ & $19.8 *(20.0 ; 25.2)$ \\
\hline \multirow{2}{*}{ ACR } & malate / glutamate & $1.44(1.32 ; 1.52)$ & $1.22(1.02 ; 1.37)$ & $1.34 *(1.12 ; 1.56)$ \\
\hline & succinate & $1.46(1.32 ; 1.54)$ & $1.24(1.22 ; 1.43)$ & $1.31 *(1.12 ; 1.36)$ \\
\hline \multirow{2}{*}{$\mathrm{RCR}$} & malate / glutamate & $1.49(1.32 ; 1.72)$ & $1.33 *(1.20 ; 1.46)$ & $1.11 *(1.44 ; 1.72)$ \\
\hline & succinate & $1.67(1.32 ; 2.1)$ & $1.24 *(1.24 ; 1.36)$ & $1.37 *(1.24 ; 1.52)$ \\
\hline \multirow{2}{*}{$\mathrm{ATP} / \mathrm{O}$} & malate / glutamate & $2.40(2.02 ; 2.62)$ & $2.25 *(2.02 ; 2.52)$ & $1.95 *(1.40 ; 2.32)$ \\
\hline & succinate & $1.82(1.62 ; 2.0)$ & $1.35 *(1.12 ; 1.42)$ & $1.30 *(1.10 ; 1.40)$ \\
\hline
\end{tabular}

Notes: The data are presented in the form of the median Me (25th, 75 th percentile).

$*-\mathrm{p}<0.05, * *-\mathrm{p}<0.001-$ the differences are statistically significant between the parameters of the control and experimental groups;

$\#-\mathrm{p}<0.05, \# \#-\mathrm{p}<0.001-$ the differences are statistically significant between the parameters of the test groups in different periods;

$\mathrm{V}_{1}$ - is speed of endogenous (basal) respiration;

$\mathrm{V}_{2}-$ is the rate of substrate-dependent respiration;

$\mathrm{V}_{3}$ - is the rate of respiration associated with phosphorylation;

$\mathrm{V}_{4}$ - is the rate of breathing after the expenditure of ADP;

ACR - coefficient of acceptor control;

$\mathrm{RCR}$ - coefficient of respiratory control;

ATP/O - coefficient of phosphorylation.

There was also a decrease in the coefficients $\mathrm{V}_{3} / \mathrm{V}_{2}, \mathrm{~V}_{3} / \mathrm{V}_{4}$ and $\mathrm{ATP} / \mathrm{O}$ in rats with 3 days BPI - by $10.3 \%, 18 \%$ and $38.1 \%(p<0.05)$, respectively, that were less $(p<0.05)$ than in untreated animals. This in general testifies to the dissociation of oxidation and phosphorylation processes in the mitochondria.

It is noteworthy that there was less pronounced reduction in the parameters of the respiration of brain mitochondria under conditions of 3 days PCI compared with the one-hour $\mathrm{BPI}$, which is probably due to the inclusion of compensation and adaptation, including collateral circulation. In respiratory activity of the brain, after adding $\mathrm{NAD}^{+}$-dependent substrates - malate/glutamate mixtures, to rats with 1 hour PCI, there was decrease in $\mathrm{V}_{2}$ by $30.2 \%(\mathrm{p}<0.05)$, in $\mathrm{V}_{3}$ - by $40.7 \%$ ( $<0.05)$, and in $\mathrm{V}_{4}-$ by $28.9 \%(\mathrm{p}<0.05)$, accounting for $70 \%, 60 \%$ and $72 \%$ respectively, versus the control value; there also was the tendency to decrease in $\mathrm{V}_{1}$ by $9.9 \%(\mathrm{p}>$ $0.05)$ (table 1). The coefficient of respiratory control $\left(\mathrm{V}_{3} / \mathrm{V}_{4}\right)$ and phosphorylation coefficient $(\mathrm{ATP} / \mathrm{O})$ in presence of succinate in animals with 1 hour BPI were by $10.3 \%$, and by $9.3 \%(p<0.05)$ respectively as less as in rats of control group.

Rats with 3 days PCI after the administration of malate/glutamate compared with sham operated animals had a decrease in $\mathrm{V}_{2}, \mathrm{~V}_{3}, \mathrm{~V}_{4}$ by $16.8 \%, 22.6 \%$ and $22.8 \%$ ( $\mathrm{p}<$ $0.05)$, respectively, along with a tendency towards decrease in the rate of basal breathing $\left(\mathrm{V}_{1}\right)$ by $5.9 \%(\mathrm{p}>0.05)$. There was also a significant drop in $\mathrm{V}_{2}, \mathrm{~V}_{3}, \mathrm{~V}_{4}$ by $30.2 \%, 40.7 \%$,
$28.9 \%(\mathrm{p}<0.05)$, accordingly, and tendency to reduce in the rate of basal breathing $\left(\mathrm{V}_{1}\right)$ by $9.9 \%(\mathrm{p}>0.05)$ in rats with 1 hour of BPI versus values of control group.

It was observed the decrease in mitochondrial breathing coefficients such as $\mathrm{V}_{3} / \mathrm{V}_{2}$ by $6.9 \%$, p $<0.05, \mathrm{~V}_{3} / \mathrm{V}_{4}-$ by $25.5 \%, \mathrm{p}<0.05$; and the phosphorylation coefficient (ATP/O) - by $18.8 \%, \mathrm{p}<0.05$.

The decrease in the coefficients of respiratory control $\left(\mathrm{V}_{3} / \mathrm{V}_{4}\right)$ and phosphorylation $(\mathrm{ATP} / \mathrm{O})$ after administration of malate/glutamate was nowhere near as expressed as after using succinate as a substrate. This indicated a greater conjugation of the oxidation and phosphorylation processes when malate/glutamate had been used. On the other hand, this also testifies to a greater vulnerability of the succinatedehydrogenase shunt to oxidative injuries compared to $\mathrm{NAD}^{+}$-dependent one, as well as to more economical oxygen consumption in the $\mathrm{NAD}^{+}$-dependent pathway due to cerebral ischemia versus the same consumption in the succinatedehydrogenase line.

\section{Discussion}

Mitochondrial dysfunction and developing energy deficiency due to PCI may cause the death of neurons by a necrotic or apoptotic mechanism that finally leads to dysfunction of not only brain but the whole organism, resulting in internal organs dysregulation as well as motor, sensory and cognitive disorders. 


\section{Conclusions}

Cerebral ischemia of various duration in rats due to the ligation of the right common carotid artery is accompanied by the inhition of the respiratory activity of the brain mitochondria and the dissociation of oxidation and phosphorylation in the mitochondria, leading to a lack of ATP in cerebral tissue induced by hypoxia. The obtained data can be used for better understanding of mechanisms of transient and stable ischemic brain lesions, which is crucial for searching new methods of their correction. Experimental partial cerebral ischemia can be used as a model for screening the means of pharmacological correction of mitochondrial respiration disorders in brain cells during cerebral ischemia.

\section{Acknowledgements}

The authors are grateful to the English translator Irina Semenchuk for the correction of the manuscript.

\section{Funding}

Grodno State Medical University grant for reagents and animals.

\section{Conflict of Interest}

The authors declare that they have no competing interests.

\section{References}

[1] Bokeria LA, Gudkova RG (2011) Diseases and congenital anomalies of the circulatory system. Moscow: NTSSSH named after A. N. Bakaleva RAMS.

[2] Bova AA, Silinovich MV (2015) Ischemic stroke: the strategy of patient management (compliance of recommendations and their real clinical application) Military medicine. 4 (37): 3035 .

[3] Directive of the European Parliament and Council (2012) 2010/63 / EU of 22.09.2010 on the protection of animals used for scientific purposes. St. Petersburg: 50.
[4] Gusev EI, Martynov MYu, Kamchatnov PR (2013) Ischemic stroke. Current state of the problem. Doktor. ru. Moscow, 5 (83): 2-7.

[5] Hossman KA (1998) Experimental models for the investigation of brain ischemia Cardiovascular Resarch. 39: 106-120.

[6] Lai JCK, Clark JB (1974) Preparation of synaptic and nonsynaptic mitochondria from mammalian brain Methods in Enzymology. 60: 51-64.

[7] Maksimovich NE (2003) The concept of the nitroxidergic system of the brain. The role of neuronal sources Journal of the Grodno State Medical University. 4: 7-11.

[8] Maksimovich NE (2004) Peculiarities of formation of the level of azoate oxide in rat blood plasma in ischemic and reperfusion injuries of the brain Regional circulation and microcirculation. 3 (11): 55-60.

[9] Maksimovich NE (2010) Modern ideas about the mechanisms of development of ischemic brain damage and ways of correction of this pathology Actual theoretical and applied aspects of pathophysiology: materials. Republican scientificpractical conference with international participation May 14, 2010-Grodno: 149-157.

[10] Rukan TA, Maksimovich NE, Zimatkin SM (2012) Morphofunctional changes in the neurons of the frontal cortex of rat brain under conditions of its ischemia-reperfusion Journal of the Grodno State Medical University. 4: 35-38.

[11] Solodkov AP, Chirkin AA (2010) Modern problems of biochemistry: textbook Vitebsk: "VSU named after P. M. Masherov ": 384.

[12] Starodubtseva OS, Begicheva S. V. (2012) Analysis of the incidence of stroke using information technology. Fundamental research.; 8 (part 2): 424-27.

[13] Suslina ZA, Piradov MA, Domashenko MA (2014) Stroke: the review of the problem (15 years later)]. Journal of Neurology and Psychiatry named after S. S. Korsakova 11: 5-13.

[14] Usova N. N., Lemeshkov L. A., Malkov A. B., Ivantsov OA, Galynovskaya N. V., Latysheva V. Ya. (2015) Diseases of the nervous system in geriatrics: A manual for physiciansGomel-99.

[15] WHO report (2013) Information Bulletin 310: www.who.int. 